\title{
Derecho de inviolabilidad del domicilio en estado de emergencia sanitaria San Martín-Tarapoto
}

\author{
Right of inviolability of the home in a state of health \\ emergency San Martin-Tarapoto
}

\author{
Cumpa Quiroz, Bismarck Segundo ${ }^{1[0000-0003-3457-5892]}$ y Chambergo \\ Chanamé, César Augusto 1[0000-0003-3998-7714] \\ ${ }^{1}$ Universidad Nacional de San Martín, Tarapoto, Perú \\ sbcumpaeunsm.edu.pe
}

Resumen. Se discute la vulneración al derecho fundamental de la Inviolabilidad del Domicilio durante el estado de emergencia sanitaria, incurrido por las Fuerzas del Orden en su afán de controlar el cumplimiento del Estado de Emergencia decretado por el Gobierno con motivo de la pandemia COVID 19 que viene afectando la salud y vida, medida adoptada al amparo del artículo 137 inciso 1 de la Constitución Política del Perú. El control del cumplimiento de la ley en este estado excepcional, debe desenvolverse en el marco de las disposiciones de la Constitución, es decir, se trata de un poder controlado, y que se desarrolla en el marco de una racionalidad jurídica cuyos aspectos la doctrina señala: (i) Las atribuciones extraordinarias deben ejercerse en el marco de la ley formal (principio de legalidad); (ii) Imposibilidad de reformar la Constitución; (iii) La finalidad suprema de las medidas excepcionales debe ser la defensa de los derechos humanos; (iv) Aplicación del principio de proporcionalidad y razonabilidad de las medidas que se decretan. La inviolabilidad de domicilio es un derecho fundamental, se puede limitar por razones expresas, bajo lo cual, debe sustentarse las intervenciones públicas para establecer si existió responsabilidades que la ley señala, restringiendo su carácter inviolable cuando se pueda determinar que se esté perpetrando algún ilícito o actos indebidos, como actos que se planifiquen al interior de viviendas, motines, sediciones, acciones terroristas u otros que puedan poner en riesgo la seguridad pública, lo que está prohibido en el mandato de emergencia.

Palabras clave: covid 19, inviolabilidad domicilio, inviolabilidad domiciliaria en estado de emergencia, inviolabilidad domiciliaria en el derecho comparado

Citar como: Cumpa

Quiroz, B. S., \&

Chambergo Chanamé, C.

A. (2021). Derecho de inviolabilidad del domicilio en estado de emergencia sanitaria San Martín-

Tarapoto. Revista Científica Ratio lure, 1(1), 62-77.

https://doi.org/10.51252/rcri .v1i1.155

Recibido: $15 / 11 / 2020$

Revisado: $15 / 12 / 2020$

Publicado: 31/01/2021
Abstract. The violation of the fundamental right of the Inviolability of the Domicile during the state of health emergency, incurred by the Forces of Order in their desire to control compliance with the State of Emergency decreed by the Government due to the COVID 19 pandemic that is affecting health and life, a measure adopted under article 137, paragraph 1 of the Political Constitution of Peru. The control of compliance with the law in this exceptional state, must be developed within the framework of the provisions of the Constitution, that is, it is a controlled power, and that is developed within the framework of a legal rationality whose aspects the doctrine indicates : (i) Extraordinary powers must be exercised within the framework of formal law (principle of legality); (ii) Impossibility of reforming the Constitution; (iii) The supreme purpose of the exceptional measures must be the defense of human rights; (iv) Application of the principle of proportionality and reasonableness of the measures that are decreed. The inviolability of domicile is a fundamental right, it can be limited for express reasons, under which, public interventions must be sustained to establish if there were responsibilities that the law indicates, restricting its inviolability when it can be determined that an illicit or offense is being perpetrated. improper acts, such as acts that are planned inside homes, riots, seditions, terrorist actions or others that may put public safety at risk, which is prohibited in the emergency mandate.

Keywords: covid 19, home inviolability, home inviolability in a state of emergency, home inviolability in comparative law 


\section{Introducción}

El Estado de Emergencia es una medida excepcional que faculta al Gobierno a asumir plenos poderes en todo el territorio. Sólo puede ser decretada en caso de perturbación de la paz o del orden interno, de catástrofe o de graves circunstancias que afecten la vida de la Nación "este último, es el caso que se investiga" por un plazo máximo de 60 días. Con respecto a la teoría "Inviolabilidad o intimidad domiciliaria", Navas, M. (2011) autora española nos alcanza lo siguiente: "Constituye el propósito de este trabajo realizar una aproximación a esta doctrina constitucional. No se pretende un análisis del derecho a la inviolabilidad domiciliaria en su conjunto, sino tan sólo de un aspecto muy particular: la concepción global que de este derecho se deriva de la jurisprudencia constitucional, particularmente de aquellos elementos cuya interpretación ha contribuido más decisivamente a darle su particular y concreta fisonomía: domicilio y bien jurídico protegido.”.

Los autores de este artículo consideran necesario para ayudar a explicar la teoría planteada, definir las dos instituciones jurídicas que la autora utiliza; primero, Inviolabilidad Domiciliaria, y segundo, Intimidad Domiciliaria: La inviolabilidad del domicilio es el derecho fundamental que permite disfrutar de la vivienda sin interrupciones ilegítimas y permite desarrollar su vida sin ser objeto de molestias. Mientras que la intimidad domiciliaria, es el derecho o facultad de desarrollar la vida privada, personal y familiar dentro del propio domicilio o morada. ¿El derecho a la intimidad o el derecho a la inviolabilidad de domicilio o, por último, el que el TC denomina como derecho a la "intimidad domiciliaria, son diferente entre sí?; nosotros diríamos que ellas se complementan e interrelacionan desde un ángulo constitucional, ya que buscan un mismo fin ¿cuál es?, el de asegurar jurídicamente que la suspensión y restricciones que el Gobierno dicte en el ejercicio de los derechos constitucionales relativos a la inviolabilidad del domicilio, éstas se realicen de la manera más pacífica, sin necesidad de recurrir a la fuerza para el cumplimiento de las disposiciones en torno al Estado de Emergencia sanitaria, y por sobre todo, actuar siempre y cuando se vulnere los presupuestos jurídicos que esta figura exige.

De acuerdo con la experiencia del Derecho Anglosajón y del Norteamericano respectivamente, el respeto y cumplimiento estrictamente obligatorio de lo ordenado en las medidas de Estado de Emergencia es fundamental y vital para que los ciudadanos puedan cumplir responsablemente con las disposiciones dadas por el Gobierno, a efectos de no poner en riesgo ni atentar contra el orden y la seguridad pública de la población y del Estado; por lo que, toda acción indebida, sediciosa o actividad delictiva que se cometa durante el periodo de emergencia incumpliéndose lo dictaminado en la orden política del estado de emergencia correspondiente, y más aún, cuando se decretan plazos de emergencia en países como Estados Unidos e Inglaterra contra amenazas terroristas o pandemias de enfermedad virulenta, lo que al darse casos indebidos o ilícitos 
sediciosos al respecto, puede implicar propiamente que las autoridades facultadas en dichos Estados puedan ejecutar sus funciones jurisdiccionales pertinentes, en que tanto, las instituciones policiales puedan realizar todas las detenciones o arrestos domiciliarios contra las personas que incumplan las medidas o reglas de la emergencia excepcional, y por ende de intervenirse a todos aquellos recintos o viviendas domiciliarias en que se llegan a realizar indebidamente toda actividad no autorizada que vulneren lo dispuesto en la política de Estado de Emergencia impuesta, mientras que los Tribunales Judiciales - Penales en tales Estados de Derecho Anglosajón, pueden emitir todas las sentencias condenatorias que sean necesarias para reprimir punitivamente de manera drástica a todos aquellos individuos que incumplan las reglas o disposiciones de fuerza establecidas bajo una orden excepcional de emergencia estatal o de carácter público.

En torno a las situaciones especiales de estados excepcionales de emergencia adoptados en los países latinoamericanos principalmente, donde en la mayoría de Estados aplicaron inicialmente una cuarentena de tipo voluntaria y limitada, con efectos tardíos de haberse aplicado la política de Estado de Emergencia Sanitaria en modo de régimen excepcional en forma total en países como Ecuador, Colombia, Chile, Brasil y México, lo que conllevó muy negativamente a que se produjese el problema de la expansión o acrecentamiento crítico de los contagios por coronavirus en la población de dichos países; los que fueron cuestionados por su reacción tardía frente a la pandemia endémica del COVID - 19, que ha llegado a provocar actualmente un aumento preocupante de la cantidad de contagiados por COVID - 19; siendo así que, la causa crítica de no haberse ejecutado una política anticipada y planificada de estado de emergencia sanitaria como régimen de excepción, de no informarse adecuadamente a la población ciudadana sobre los peligros de contagio de la enfermedad referida y de las sanciones como castigos punitivos que se podían llegar a aplicar por incumplimiento de las normas de cuarentena; y de no haberse limitado el ejercicio de la inviolabilidad de domicilio en los casos pertinentemente excepcionales, lo que produjo alarmantemente el brote epidémico del coronavirus y que hasta el momento se tengan los riesgos de que se lleguen a producir rebrotes de la enfermedad referida, como el ya ocurrido en los Estados Unidos de Norteamérica.

Esta problemática corroborada por el autor chileno San Martín (2020), quien sostuvo acerca de que "en Chile, la aplicación tardía tanto de la política de régimen excepcional del estado de emergencia sanitaria en forma total como de la cuarentena obligatoria, produjo desánimo y el desacato por parte de la población chilena" (p. 7). Nos quiere decir que, al no haberse cumplido en su gran mayoría con las reglas o medidas obligatorias de la cuarentena, se han casos críticos y de denuncias sobre aglomeraciones ciudadanas prohibidas o clandestinas en lugares públicos, sobre domicilios privados en que inescrupulosos dueños propietarios de viviendas han realizado reuniones privadas en forma aglomerada, estando sumamente prohibido y sancionado de hacerlo; 
exponiéndose riesgosamente al contagio peligroso del COVID-19, poniendo en peligro a su propia vida y salud, como la de sus familiares e hijos menores de edad y de otros; todo ello, por no acatar las medidas impuestas para combatir la emergencia sanitaria.

La importancia de este artículo científico radica en que, ofreceremos todos los fundamentos dogmáticos - jurídicos explícitos a las fuerzas del orden y operadores jurídicos, a efectos de que realicen todas las acciones requeridas que limiten el ejercicio del derecho de inviolabilidad de domicilio cuando su ejecución indebida por parte de malos ciudadanos que utilicen sus viviendas, realicen reuniones clandestinas que puedan poner a terceros en grave riesgo de contagio infeccioso de coronavirus.

Mientras que, el objetivo del presente circunda en explicar acerca de la afectación justificable al derecho fundamental de la inviolabilidad de domicilio en el desarrollo del periodo de estado de emergencia sanitaria en el departamento de San Martín, desde el inicio de la propagación pandémica hasta la fecha.

\section{Materiales y Métodos}

\section{El diseño y el sitio de estudio}

El diseño de esta investigación consistirá en un estudio correlacional, desarrollada por profesionales de la Escuela de Posgrado de la Universidad César Vallejo, en Perú con sede en la ciudad de Tarapoto, que se pueda regular y determinar en qué casos se podría restringir el derecho fundamental de la inviolabilidad de domicilio durante el periodo de emergencia sanitaria, ya que actualmente, a esta institución jurídica se está conduciendo temerariamente a su desnaturalización, permitiéndose la vulneración de este derecho fundamental de las personas. La obtención de los datos, fue realizada en doce días, del 29 de noviembre al 09 de diciembre del año 2020.

\section{Criterios de elegibilidad}

Tipos de participantes: se incluyeron estudios que involucraban principalmente a personas adultas mayor, así como aquellas que presentan enfermedades susceptibles al contagio de COVID 19 que radican en la ciudad de Tarapoto, siendo excluidas aquellas bibliografías indexadas que datan antes del año 2015, y que, gracias a la ubicuidad de la biblioteca digital de la Universidad César Vallejo, fue posible obtener fuentes del año presente, lo que da mayor realce y validez al presente artículo científico. Es oportuno a precisar que, los investigadores han recurrido a la bibliografía de autores internacionales y nacionales que han publicado textos relacionados al tema materia de investigación. 
Tipos de estudios: Gracias a la diversidad de información existente sobre el tema tratado, ha sido posible plantear nuevos conocimientos y teorías sobre el tema, e identificar los diseños de estudio por el nivel de pruebas encontrados y ofrecidos por la doctrina y jurisprudencia respectivamente. Tipos de resultados: Se seleccionaron como resultados primarios los siguientes: estudios con rigor científico, sentencias jurisdiccionales, doctrina jurídica nacional y comparada, investigaciones reales, experiencias de autores entre otros que coadyuvaron al éxito en la formulación del presente artículo.

\section{Búsqueda de estudios}

Elementalmente se realizó una búsqueda manual utilizando las referencias de los estudios primarios y secundarios encontrados en la búsqueda electrónica, siendo posible ubicarlos en la base de datos Ebsco que cuenta la plataforma virtual de la Universidad César Vallejo, siendo filtrado como a continuación se esquematiza:

TRILCE: Servicios varios; Biblioteca; Seleccionar la condición de alumno de Doctorado; Seleccionar el enlace Recursos Digitales; BIBLIOTECA VIRTUAL donde se encuentra el buscador integral ubicando la herramienta de EBSCO aperturándolo y encuentra finalmente Discovery Service para Universidad Cesar Vallejo, en donde se podrá navegar fácilmente ingresando las palabras claves sobre el tema que investiga "inviolabilidad del domicilio COVID 19", y se ubicó la diversidad de fuentes bibliográficas que ofrece, tal que, fue suficiente esta única base de datos para el desarrollo del mismo.

\section{Selección de estudios}

El proceso de selección de los estudios fue realizado por el doctorando con guía del docente de nuestra experiencia curricular Seminario IV de la Escuela de Posgrado de la Universidad César Vallejo. Los estudios se seleccionaron en dos etapas. El primer paso consistió en revisar y seleccionar los títulos afines al tema examinado, procediendo luego a efectuar un resumen sustancial de las referencias encontradas con nuestra estrategia de búsqueda; se seleccionaron los estudios potencialmente elegibles quedando un total de quince conforme a lo presentado en el producto académico de la sesión 2. El segundo paso consistió en revisar el texto completo de los estudios preseleccionados que ofrece la biblioteca virtual UCV en formatos PDF, lo que permitió confirmar su elegibilidad o capacidad legal académica. 3. El tercer paso consistió en seleccionar y revisar textos de autores internacionales y nacionales que coligen con el tema, extrayendo glosas de interés a la investigación, siendo en un total de cuatro textos.

\section{Resultados y discusiones}

Ingresado a Ebsco la palabra clave "inviolabilidad domicilio covid 19", dieron 49 referencias todas ellas únicamente del año 2020 teniendo en consideración que dicha pandemia se dio inicio

Citar como: Cumpa Quiroz, B. S., \& Chambergo Chanamé, C. A. (2021). Derecho de inviolabilidad del domicilio en estado de emergencia sanitaria San Martín-Tarapoto. Revista Científica Ratio lure, 1(1), 62 77. https://doi.org/10.51252/rcri.v1i1.155 
Vol. 1, Núm. 1, ene-jun, 2021

en el Continente de Asia en noviembre 2019 expandiéndose en Perú en marzo 2020, por la actualidad del tema e información obtenida, fue suficiente el número encontrado para haber seleccionado 10 referencias y que luego de ser leídas se confirmó su elegibilidad. Los resultados de los 10 estudios restantes se presentan a continuación de manera descriptiva, ya que la naturaleza de ellos no permite ningún otro tipo de análisis, de igual manera, la tabla 1 presenta los resultados de manera concisa (serán presentados en el siguiente producto académico).

Tabla 1

Autores de artículos científicos, y revistas indexadas cuyos contenidos fortalecen la investigación: Derecho de la inviolabilidad del domicilio en estado de emergencia sanitaria San Martín-Tarapoto

\begin{tabular}{|c|c|c|c|c|}
\hline Autores & $\begin{array}{l}\text { Tipo de } \\
\text { Estudio }\end{array}$ & Métodos & Resultados & Conclusiones \\
\hline $\begin{array}{l}\text { Riofrío Martínez-Villalba J.C. } \\
\text { (2020); "Estado de extremísima } \\
\text { excepción reconocido tácitamente } \\
\text { en la constitución y su aplicación } \\
\text { al sector privado" } 30 \text { jun } 2020 \text {. }\end{array}$ & $\begin{array}{l}\text { Artículo } \\
\text { Original }\end{array}$ & $\begin{array}{l}\text { Método Histórico, y se } \\
\text { hace un análisis del } \\
\text { derecho comparado. }\end{array}$ & $\begin{array}{lr}49 & \text { referencias } \\
\text { bibliográficas encontradas } \\
\text { en Ebsco-UCV, } r \text { fueron } \\
\text { seleccionadas } \\
\text { excluyendo 39. }\end{array}$ & $\begin{array}{l}\mathbf{1}^{\circ} \text { El régimen de excepción ha } \\
\text { evolucionado por más de } 2,500 \\
\text { años. 2 } 2^{\circ} \text { El derecho de } \\
\text { necesidad y los } \\
\text { constitucionales } \\
\text { autoconservación, necesidad, } \\
\text { proporcionalidad } \\
\text { razonabilidad }\end{array}$ \\
\hline
\end{tabular}

García Otero, R. (2020); "Derechos Humanos y Mecanismos de control internacional en el marco de la pandemia Covid-19: reflexión desde el control de convencionalidad". 30 ago 2020.

Sánchez-Sánchez, M y W (2020); "Falencias en derechos humanos en tiempos de pandemia del coronavirus". 30 jun 2020.

Figueroa Gutarra, E. (2020); "Estados de excepción, COVID19 y derechos fundamentales". 08 jun 2020 .

Gonzáles Correo, A. (2020); "Ansiedad en tiempos de aislamiento social por COVID-19. Chota, Perú, 2020".

Sánchez Sanchez, A. (2020); "COVID-19 y su relación con la ciencia jurídica desde la perspectiva de México". 30 set 2020.

Artículo de

Revisión

Artículo de Revisión

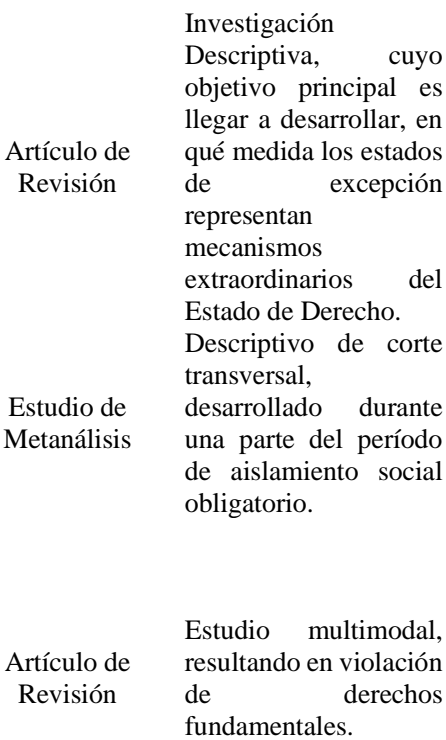
en Ebsco-UCV, fueron seleccionada excluyendo 39 . $\begin{array}{lr}49 & \text { referencias } \\ \text { bibliográficas } & \text { encontradas }\end{array}$ en Ebsco-UCV, fueron seleccionadas excluyendo 39 10 conocimientos $y$ nuevos campos de investigación sin un fin práctico específico e inmediato.

49 bibliográficas encontrada en Ebsco-UCV, fueron seleccionadas excluyendo 39 10 , intensidad de los problemas

10

a ansiedad alcanzó a $43,3 \%$ de los participantes $20,9 \%$ presentan ansiedad leve, $13,4 \%$ moderada, y $9 \%$ severa.

Por la temporalidad en que se realiza el estudio no es posible abordar personalmente a los individuos involucrados, como son los policías, los médicos, las enfermeras, las personas en general, los pacientes y sus familiares, pero se considera que se $\mathbf{1}^{\circ}$ Desde un enfoque jurídico internacional, las tensiones internas entre las institucione de los Estados, debe ser sopesada con base en el derecho internacional de los derechos humanos

Existe una discordancia entre el discurso de la CIDH, que reconoce la desigualdad socio económica y limitaciones para la aplicación de los Derechos Humanos de América, y sus pretensiones aspiraciones de garantía de los mismos en época de la pandemia de COVID-19, una enfermedad altamente contagiosa.

$1^{\circ}$ Mantener la viabilidad de sometimiento a control de los actos de poder en relación con as limitaciones de los derechos ciudadanos protegidos por la Convención Americana.

Los niveles de ansiedad durante una pandemia pueden llegar a reducirse cuando la duración del aislamiento es lo más corta posible.

Existe una garantía constitucional llamada juicio de amparo, el cual procede contra ese tipo de actos de autoridad, con lo que se garantizan los derechos humanos. 
cumple con el método planteado.

Navas Sánchez, M. (2011); “¿Inviolabilidad o Intimidad Domiciliaria? A propósito de la jurisprudencia

constitucional sobre el derecho fundamental a la inviolabilidad del domicilio".
Tribunal Supremo, Sala de lo Contencioso-Administrativo (2019); Sentencia 10 octubre 2019; "La solicitud de entrada y registro en domicilio acordada en un procedimiento de comprobación e inspección debe atender a criterios de necesidad y proporcionalidad"; 01 dic 2019.

González Cussac, J. (2014); "Intromisión en la intimidad y CNI. Crítica al modelo español de control judicial previo". 13 may 2014.

Artículo de Revisión

Restrepo García, J. (2012); "El contenido del numeral $1^{\circ}$ del artículo 230 del CPP frente al bloque de constitucionalidad ¿Se respeta el derecho a la intimidad con la simple autorización expresa del propietario o tenedor de allanar su inmueble?". 17 abr 2012.

Artículo de Revisión
49 referencias bibliográficas encontradas en Ebsco-UCV, fueron seleccionadas excluyendo 39 .

\section{Descriptivo}

Explicativo, ya que utiliza doctrina de autores connotados

Artículo Original

\begin{tabular}{|c|c|}
\hline & $\begin{array}{l}\text { Realizado a través de } \\
\text { un documento formal } \\
\text { judicial denominado: } \\
\text { Tribunal Supremo, }\end{array}$ \\
\hline $\begin{array}{l}\text { Estudio } \\
\text { de Caso }\end{array}$ & $\begin{array}{ll}\text { Sala de lo } \\
\text { Contencioso- } \\
\text { administrativo, } \\
\text { Sentencia } \\
\text { 1343/2019, 10 oct. } \\
\text { Rec. 2818/2017. }\end{array}$ \\
\hline $\begin{array}{l}\text { Artículo de } \\
\text { Revisión }\end{array}$ & $\begin{array}{l}\text { Describir sucintamente } \\
\text { el régimen establecido } \\
\text { en esta norma. }\end{array}$ \\
\hline
\end{tabular}

Se cotejan algunas producida por el Tribunal

Constitucional

Español. como de jurisprudencia
Su actuación ha de guiarse por la lógica de la legalidad («seguir

una regla»), que es la propia de un juez; o en atención la especial materia enjuiciada, deberán guiarse por la lógica de análisis de las consecuencias (necesidad y oportunidad). El magistrado pierde hasta cierto punto su legitimidad constitucional, es decir, su actuación como juez, y a la vez aparece como una persona escasamente preparada técnicamente para esa clase de decisiones y carente de competencias jurídicas en materia de seguridad $y$ defensa nacional.

Se dan por los tratados internacionales.
Se desprende que el Tribunal Constitucional sostiene una concreta y determinada concepción

del derecho fundamental a la inviolabilidad del domicilio (art. 18.2 CE). Se trata de una configuración caracterizada por su fuerte interrelación y dependencia respecto del derecho a la intimidad personal y familiar (art. 18.1 CE) siendo, además, destacable que el Tribunal Constitucional interpreta aquí la noción de intimidad en un sentido estricto y personalista, alejada de la noción amplia de intimidad que maneja el

Tribunal Europeo de Derechos Humanos.

No era necesario sacrificar el derecho

fundamental a la inviolabilidad del domicilio como única forma -principio

de subsidiariedad- de garantizar el cumplimiento de todos los requisitos establecidos por la ley.

La firme tradición democrática y garantista construida a lo largo y ancho de la historia jurídicopenal y constitucional de la humanidad.

Cuenta con un verdadero muro jurídico de contención y protección de las más elementales y preciadas garantías del ser humano, que es la coraza de protección del ciudadano frente al Estado.

Del primer artículo: Presentado por Martínez-Villalba (2020) cuyo tipo de estudio corresponde a una investigación de Artículo Original, realizada en Ecuador que tuvo sustento inicial en la historia política universal con relación al estado de excepción como los ocurridos en el imperio Romano durante la época de la República, después que se aboliera la Monarquía en el año 509 a.c. sigue describiendo el autor diciendo que, ante el temor inminente de las guerras se resolvió 
nombrar un praetor máximus o dictador, embestido con plena autoridad frente a los magistrados y cónsules y todos los poderes existentes de la época, a fin de enfrentar la emergencia militar o para emprender una tarea específica de carácter excepcional. El dictador solo podía actuar dentro de la esfera de autoridad a la que estaba destinado, y debía renunciar a su cargo al cabo de seis meses, o una vez cumplida la tarea encomendada. Llegado al país ecuatoriano, el autor indica que, varias constituciones en una primera época señalaban que durante el estado de excepción el gobierno podía suspender cualquier derecho, salvo los mencionados en algún lugar. Pero, como el abuso de la institución continuó dándose las limitaciones al régimen de excepción fueron creciendo, sobre todo en el ámbito nacional. Hoy está regulada esta materia en la Constitución ecuatoriana. Ahora la norma general dice que no cabe suspender ningún derecho, sino solo los expresamente establecidos en la constitución (la excepción pasó a ser la regla general).

El método utilizado fue el método histórico y se hace un análisis del derecho comparado. Se utiliza la noción lata de "estado de excepción", que comprende los estados de: "emergencia", "alarma", "catástrofe", "sitio", "guerra" o "calamidad". Después de una introducción, se expone cómo el estado de excepción ha evolucionado durante los siglos, y cómo se han ido limitando progresivamente los poderes conferidos al mandatario, hasta llegar en algunos países a constituir un estado de excepción débil. Luego se observan las deficiencias de ese estado de excepción débil para afrontar crisis como la pandémica del coronavirus covid-19. Tras constatar lo anterior, aplicando los principios de necesidad, autoconservación, proporcionalidad y razonabilidad se propone la existencia de un "estado de extremísima excepción" que permita a las autoridades atender de mejor manera las crisis. Se señala cómo podría funcionar este nuevo régimen y cuáles serían sus limitantes. Fijada la noción de este nuevo régimen de excepción, y delimitado su alcance, se analiza cuánta incidencia podría tener en el sector privado. Finalmente, se analizan las repercusiones en la fijación de la responsabilidad jurídica, tanto en el sector público como en el sector privado.

Los resultados en la obtención de las fuentes utilizadas, primero fueron del producto de haber obtenido 49 referencias bibliográficas encontradas en Ebsco-UCV, y segundo, entre las encontradas fueron seleccionadas 10 entre las cuales está el autor in examine, excluyendo 39 estudios que no cumplían con nuestros criterios de investigación.

Las conclusiones abordadas producto de nuestro estudio, obtuvimos 2, ellas son: $\mathbf{1}^{\circ}$ El régimen de excepción ha evolucionado por más de 2,500 años. $2^{\circ}$ El derecho de necesidad y los principios constitucionales de autoconservación, necesidad, proporcionalidad y razonabilidad justifican que en los casos de emergencias mayores haya un "estado de extremísima excepción", donde se otorguen a las autoridades mayores poderes mayores a los poderes limitados de un régimen de excepción débil— con el fin exclusivo de enfrentar la crisis. Todo régimen de excepción siempre 
debe ser gradual: a mayores calamidades, mayores poderes para enfrentarla. En ocasiones ha de aplicarse este principio incluso superando la literalidad de la ley.

Del segundo artículo: Presentado por García Otero, R. (2020) cuyo tipo de estudio corresponde a una investigación de Artículo Original, realizada en Colombia que tuvo sustento la pandemia originada por la rápida propagación del virus denominado Covid-19, que, de acuerdo a la Organización Mundial de la Salud - OMS, empezó a afectar a gran parte de la población ubicada en la República Popular de China y, desde entonces, su expansión ha sido inminente a todos los países del mundo, ha provocado una inesperada alteración a la forma natural de vivir, restringiendo y paralizando derechos fundamentales y el desarrollo económico de los pueblos. Este propósito, conlleva a la inclusión de todos los integrantes de una sociedad, sin atender condición social, económica, política o religiosa, asegurando su inclusión en las diversas tomas de decisiones referentes a las medidas políticas asumidas para la protección de las comunidades, incluyendo a voceros, de manera que todo el proceso crítico sea llevado de una manera democrática (ONUSIDA 2020). En tal sentido, el empoderamiento de las comunidades juega un papel importante en el accionar y gestión de las autoridades, previa información transparente y precisa sobre la realidad de los hechos acontecidos en relación con la pandemia. En el mismo sentido, la utilización del derecho penal y policivo, como mecanismo para regular el comportamiento de las personas y prevenir la transmisión del virus, termina teniendo un resultado severo en contra de los derechos humanos, pues afecta la persona y personalidad del individuo, así como el efecto colectivo de la sociedad. Tal efecto genera descontento, desconfianza y estigmatización de la situación pandémica, imperando la arbitrariedad a los miembros de una sociedad. Estos términos, orientan a la supervisión y rendición de cuentas de parte de los gobiernos sobre la salud pública, por cuanto es un deber general de los Estados (que se encuentren enmarcados dentro de un sistema político de Estado democrático y de Derecho) el respeto y garantía por las normas fundamentales en materia de derechos humanos, siendo la acción u omisión responsabilidad directa de los gobernantes, la comunidad tiene el poder de cuestionar el accionar de los gobernantes en situaciones comunes o inclusive de emergencia, pues tales situaciones se prestan para el desapego de las leyes, al ser discriminatorias, desproporcionadas o en base a razones no apropiadas; lo cual, faculta a la persona para reclamar los abusos de tales derechos y recibir una justa reparación, cumpliendo con las políticas de Estado, las leyes y los principios universales en materia de derechos humanos.

El método utilizado se realiza en primer lugar, una descripción a través del análisis teóricoobservacional de la profundización o intensidad de los problemas que el paso del Covid-19 va dejando en todos los ámbitos de la sociedad y, los retos que la humanidad debe afrontar para buscar un equilibrio en la salvaguarda de derechos inalienables como la vida y salud y, al tiempo, ofrecer oportunidades para el desarrollo y crecimiento económicos de los pueblos. 
Posteriormente, se describe la situación excepcional en Colombia y sus dimensiones jurídicas, como referente al contexto jurídico-político que viven los Estados latinoamericanos en aras de contener o superar la pandemia. Por último, se aborda desde el enfoque analítico-hermenéutico, el papel que cumple en el escenario del derecho internacional de los derechos humanos, el control de convencionalidad para asegurar la integración de las normas internacionales-regionales con las nacionales o internas y, revisar su pertenencia para que los mandatarios armonicen de posiciones políticas y asegurar la efectiva protección de los derechos humanos, máxime, en época de crisis o emergencias regionales.

Los resultados en la obtención de las fuentes utilizadas, primero fueron del producto de haber obtenido 49 referencias bibliográficas encontradas en Ebsco-UCV, y segundo, entre las encontradas fueron seleccionadas 10 entre las cuales está el autor in examine, excluyendo 39 estudios que no cumplían con nuestros criterios de investigación.

Las conclusiones abordadas producto de nuestro estudio, obtuvimos los siguientes: $1^{\circ}$ Desde un enfoque jurídico internacional, las tensiones internas entre las instituciones de los Estados, debe ser sopesada con base en el derecho internacional de los derechos humanos, así como lo regulado en los distintos instrumentos jurídicos internacionales en la materia, con el fin de dar prioridad al respeto y promoción de tales derechos, la salud y la dignidad humana. $2^{\circ}$ En el caso colombiano, el control de la constitucionalidad data del año 1991, en cuanto con el nacimiento de la Constitución Política de Colombia, el cual brindaba la protección a las normas internas o supremas que estuvieran en detrimento con los principios y valores plasmados en la misma Carta Magna. El garante de la constitucionalidad en el país colombiano es la Corte Constitucional, la cual tiene la facultad de revisar las leyes, decretos y actos reformables por la misma constitución. En tal sentido, de la aplicación del control de la constitucionalidad, le nace la posibilidad a los jueces nacionales de aplicar el control de la convencionalidad, por cuanto el derecho internacional en materia de derechos humanos, se encuentra intrínseco en el derecho interno de los Estados, una vez que cada uno de estos ratifica el instrumento jurídico, es así, que en el caso colombiano, los jueces tienen la obligación de aplicar tal control cuando se vean tales derechos fundamentales lesionados. En tal situación, los jueces tienen la obligación de aplicar el control de la convencionalidad, conforme el contenido y alcance de lo establecido en la Convención Americana, así como las interpretaciones y criterios establecidos por la CIDH, siendo la motivación fundamental para el ejercicio de tal control por parte de los jueces constitucionales $\mathrm{u}$ ordinarios, según sea el caso, pues tales preceptos protegen y garantizan los derechos fundamentales.

Citar como: Cumpa Quiroz, B. S., \& Chambergo Chanamé, C. A. (2021). Derecho de inviolabilidad del domicilio en estado de emergencia sanitaria San Martín-Tarapoto. Revista Científica Ratio lure, 1(1), 62 77. https://doi.org/10.51252/rcri.v1i1.155 


\section{Discusiones}

Por razones de estrategia de investigación, a continuación, señalamos los cinco "de diez ver tabla 1" principales hallazgos encontrados en el decurso de la presente investigación, a los cuales, precisaremos su significado e importancia de los estudios realizados, y que queda conforme al detalle siguiente:

Con relación al estudio de Riofrío Martínez-Villalba J.C. (2020), "Estado de extremísima excepción reconocido tácitamente en la constitución y su aplicación al sector privado"; nos deja claro que, históricamente los Jefes de Estado han venido utilizando la declaratoria de estado de emergencia, para verse beneficiado políticamente y/o obtener beneficios personales, como así lo evidencia los hechos actuales que vienen ocurriendo en Perú desde la declaratoria de emergencia sanitaria por el COVID-19 desde el mes de Marzo hasta la fecha, inconducta que están siendo investigados tanto por el Poder Legislativo como por el Ministerio Público respectivamente. Con relación al control del cumplimiento de la norma en lo que respecta al aislamiento social obligatorio o de la cuarentena obligatoria que debe cumplir la población, se pudo ver que, las fuerzas del orden venían excediéndose en el ejercicio de su función cuando tenían que ingresar a los domicilios en donde presuntamente se realizaban reuniones prohibidas, dando muestra evidente que sus acciones no obedecían a una guía de procedimientos donde señale y precise el cómo de su actuar para estos casos. Desde que los hechos de corrupción cometidos durante la pandemia han sido y vienen investigándose, parece que ello, los adormecido y ha hecho retroceder a no seguir cometiendo los excesos en sus intervenciones, pero, por otro lado, también podemos aseverar que, esta indiferencia <<diríamos obligada〉>, no hace bien para la lucha contra el COVID-19 ya que lo que se obtiene es que exista mayor número de ciudadanos infectados. Esta situación irregular generada por el gobierno, conlleva a un estado de sumo peligro para la población, por un lado, a que no se logre la obtención de la vacuna contra el virus trayendo más muertes; y, por otro lado, a que los pobladores no cumplan con las medidas que ayuden a prevenir la expansión de la enfermedad pandémica, y así los encargados del control sigan cometiendo mayores abusos al ingresar abusivamente a los domicilios sin motivo que lo sustente, vulnerándose el principio fundamental de la inviolabilidad del domicilio.

Del estudio de García Otero, R. (2020), "Derechos Humanos y Mecanismos de control internacional en el marco de la pandemia Covid-19: reflexión desde el control de convencionalidad". Esto significa que, la población debe estar siempre empoderada en cualquier estado en se encuentre el país, incluso, en el estado actual por emergencia sanitaria COVID-19; sin embargo, el Estado peruano lo debilita más aún, ya que la autoridad no lidera con honestidad en su obligación funcional de combatir este mal mundial y que ya viene resultando en nuestro territorio cerca de 60,000 habitantes muertos. La negativa de ello está encuadrada a que las fuerzas del orden no cumplen cabalmente su función de control sin violar el domicilio ilegalmente, no

Citar como: Cumpa Quiroz, B. S., \& Chambergo Chanamé, C. A. (2021). Derecho de inviolabilidad del domicilio en estado de emergencia sanitaria San Martín-Tarapoto. Revista Científica Ratio lure, 1(1), 6277. https://doi.org/10.51252/rcri.v1i1.155 
estando acorde tanto a las normas jurídicas internas, como a los instrumentos internacionales establecidos para la protección de los derechos humanos; de allí, que el autor establece y pide reflexión desde el control de convencionalidad. Estos desfaces y desproporciones que vienen demostrando la autoridad en sus diferentes intervenciones por controlar, terminan por debilitar la política de seguridad que se tenga para luchar contra la pandemia desatada, generando pánico en el poblador e imperando el abuso de autoridad.

Con relación al autor Figueroa Gutarra, E. (2020), "Estados de excepción, COVID-19 y derechos fundamentales"; se puede establecer que, el estudioso nos quiere decir sí la vulneración a los derechos fundamentales consagrados en nuestra carta política <<entre ellos el de inviolabilidad al domicilio materia de investigación >> resulta necesario ampliar su contenido, ya que ellos vienen siendo vulnerados en el estado de emergencia sanitaria por la que estamos pasando, vulneración claro está, de parte de las fuerzas del orden. O en otro caso, también se refiere el autor si resulta pertinente poner de relieve la dimensión jurídica de los derechos fundamentales. Considero que, lo más apropiado resultaría el segundo planteamiento, que consistiría, por una parte, dar mayor instrucción formativa a los miembros encargados del control y hacer cumplir la ley, debiendo ser orientada a adquirir conocimientos y técnicas apropiadas para que su función de control cumpla de una forma más profesional, y sobre todo con respeto irrestricto a los derechos humanos y fundamentales de la persona.

El estudio correspondiente a Gonzáles Correo, A. (2020), "Ansiedad en tiempos de aislamiento social por COVID-19. Chota, Perú, 2020"; estudio que es de suma importancia para el tema in examine, ya que lo hallado significa que, la población peruana en general se encuentra en un grave estado de ansiedad producto del aislamiento social obligatorio por COVID-19, con proyección a que aumente, teniendo en cuenta que, la investigación fue realizada cuando la disposición del gobierno fuera dada en sus primeros doce días desde que entrara en vigencia el Decreto de Urgencia; pues ahora <<dic 2020>>, ya ha sumado casi nueve meses, tiempo en el cual también se ha incrementado la desatención casi total de parte del Estado para con su comunidad al ser enterados que no hizo nada para adquirir la vacuna, actitud negativa que va en desmedro de la moral poblacional - teniéndose en cuenta que éste fue un estudio psicológico -.

El estudio de Sánchez Sanchez, A. (2020), “COVID-19 y su relación con la ciencia jurídica desde la perspectiva de México"; el autor mexicano nos quiere decir que, la ciencia del Derecho auxilia a los Estados para encontrar las mejores políticas públicas y preparar a los actores de esta lucha que incluye a la población, para afrontar eficientemente en la lucha contra esta enfermedad instalada también en el país de México, y así no se cometan vulneraciones a los derechos fundamentales en época de pandemia. Para hacer posible ello, el estado mexicano recurre a los campos del Derecho de la legalidad, constitucionalidad y convencionalidad, es de esta forma que, las fuerzas del orden de hacer cumplir la ley no vulneran los derechos ciudadanos <<entre ellos 
el de inviolabilidad del domicilio〉>. Sumado a ello, a la fecha en que se formula la presente investigación, aseveramos en decir que, México es uno de los países que han adquirido la vacuna para prevenir a que sus ciudadanos sigan contagiándose, acto gubernamental que ha sido bien recibido por sus ciudadanos, a esto, si sumamos los principios del derecho mencionados que vienen practicando, podremos asegurar que, el Estado mexicano está en buen camino para vencer la pandemia, a pesar de su extensa población.

\section{Conclusiones}

El régimen de excepción ha evolucionado por más de 2,500 años, presentadas en su inicio productos de las guerras por querer ocupar territorios de otros Estados, pero que no fueron previstas para situaciones de pandemia que pone en riesgo la vida de las personas, de allí que algunos Estados - entre los cuales el Perú -, no cumplen para ello lo previsto en las normas internacionales que resguardan los derechos humanos. El derecho de necesidad y los principios constitucionales de autoconservación, necesidad, proporcionalidad y razonabilidad justifican que en los casos de emergencias mayores haya un "estado de extremísima excepción", donde se otorguen a las autoridades mayores poderes a los poderes limitados de un régimen de excepción débil, con el fin exclusivo de enfrentar la crisis. Todo régimen de excepción siempre debe ser gradual: a mayores calamidades, mayores poderes para enfrentarla. En ocasiones ha de aplicarse este principio incluso superando la literalidad de la ley, pero, sin vulnerar los derechos fundamentales de las personas. En esta primera conclusión podríamos decir que la solución al problema pandémico actual, en general, más es político que jurídico, sin embargo, no deja de ser importante que el Derecho aporte para que contribuya a la solución, obteniendo nuevas reformas, normas, disposiciones entre otras para que el Estado cumpla con eficacia su función de hacer cumplir la ley bajo estado de emergencia sanitaria, sin vulnerar el derecho a la inviolabilidad del domicilio, dicho así en este caso por ser materia de nuestra investigación.

Desde un enfoque jurídico internacional, las tensiones internas entre las instituciones de los Estados, debe ser sopesada con base en el Derecho Internacional de los Derechos Humanos, así como lo regulado en los distintos instrumentos jurídicos internacionales en la materia, con el fin de dar prioridad al respeto y promoción de tales derechos, la salud y la dignidad humana. En el caso colombiano, el control de la constitucionalidad data del año 1991, el cual brindaba la protección a las normas internas o supremas que estuvieran en detrimento con los principios y valores plasmados en la misma Carta Magna. El garante de la constitucionalidad en el país colombiano es la Corte Constitucional, la cual tiene la facultad de revisar las leyes, decretos y actos reformables por la misma constitución. En tal sentido, de la aplicación del control de la constitucionalidad, le nace la posibilidad a los jueces nacionales de aplicar el control de la convencionalidad, por cuanto el derecho internacional en materia de derechos humanos, se encuentra intrínseco en el derecho interno de los Estados, una vez que cada uno de estos ratifica 
el instrumento jurídico, es así, que en el caso colombiano, los jueces tienen la obligación de aplicar tal control cuando se vean tales derechos fundamentales lesionados.

En tal situación, los jueces tienen la obligación de aplicar el control de la convencionalidad, conforme el contenido y alcance de lo establecido en la Convención Americana, así como las interpretaciones y criterios establecidos por la Corte Interamericana de Derechos Humanos (CIDH), siendo la motivación fundamental para el ejercicio de tal control por parte de los jueces constitucionales u ordinarios, según sea el caso, pues tales preceptos protegen y garantizan los derechos fundamentales.

Debe de mantenerse la viabilidad de sometimiento a control de los actos de poder en relación con las limitaciones de los derechos ciudadanos protegidos por la Convención Americana, en la medida que no es una facultad irrestricta de los Estados que, mediante el argumento de las limitaciones de los estados de excepción, se suspendan, anulen o minimicen los derechos básicos de los ciudadanos; en estos casos, cuando la ley así lo señale, entonces los Estados deberán adoptar en forma minuciosa y amplia las mejores disposiciones que permitan resguardar los derechos humanos y fundamentales que a toda persona por su naturaleza les corresponde. En el mejor de los casos, habrá que redefinir las generaciones de derechos fundamentales desde una nueva perspectiva unitaria, para demandar mayores derechos civiles y políticos, sociales y económicos impulsadas por las políticas públicas del Estado, máxime cuando las poblaciones se encuentren en grave riesgo de perder la vida.

Los niveles de ansiedad durante una pandemia pueden llegar a reducirse cuando la duración del aislamiento es lo más corta posible, la persona recibe información y orientación precisa, se informa de medios de comunicación confiables, cuenta con el suministro suficiente para disminuir la frecuencia de salidas, tiene una situación financiera estable, realiza actividades lúdico/recreativas y cuando mejora la comunicación (física o virtual). Esta forma de superar la ansiedad poblacional como producto de la pandemia, deberá constituirse en una política pública de importancia, que obligatoriamente se le debe hacer llegar a la población para preservar adecuadamente su estado emocional, que no podría ser resquebrajada por la pandemia propiamente, si no también por, la crisis económica, de atención salud, despidos masivos laborales, cierres de empresas etc.

El Estado mexicano, aborda la relación que se encuentra entre el COVID-19 y la ciencia jurídica, radica en que el Estado es el responsable de garantizar la salud de los habitantes de su país, lo que debe cumplir actuando con apego al marco de legalidad, constitucionalidad y convencionalidad, dicho de otra forma, con estricto apego a lo establecido en los derechos fundamentales <<inviolabilidad del domicilio〉> de las personas en México, cuando esto no es así, existe una garantía constitucional llamada juicio de amparo, el cual procede contra ese tipo de actos de autoridad, con lo que se garantizan los derechos humanos.

Citar como: Cumpa Quiroz, B. S., \& Chambergo Chanamé, C. A. (2021). Derecho de inviolabilidad del domicilio en estado de emergencia sanitaria San Martín-Tarapoto. Revista Científica Ratio lure, 1(1), 62 77. https://doi.org/10.51252/rcri.v1i1.155 


\section{Referencias bibliográficas}

Borea Odría, A. (2016), "Manual de la Constitución, para qué sirve y cómo defenderte", 1ra. Ed. Los estados de excepción, pp. 847-858.

Figueroa Gutarra, E. (2020), "Estados de excepción, COVID-19 y derechos fundamentales", Revista Oficial del poder judicial - Perú, 11(13); 407-438.

García Otero, R. (2020), "Derechos Humanos y Mecanismos de control internacional en el marco de la pandemia Covid-19: reflexión desde el control de convencionalidad". Utopía y Praxis Latinoamericana, $N^{\circ} 25$, agosto 2020, pp. 116-132. Universidad del Zulia - Maracaibo Venezuela.

García Toma, V. (2005), "Teoría del Estado y Derecho Constitucional”, 1ra. Ed. El régimen de excepción y los derechos constitucionales, pp. 630-635.

Gonzáles Correo, A. (2020), “Ansiedad en tiempos de aislamiento social por COVID-19. Chota, Perú, 2020”, DOI: https://doi.org/10.15446/av.enferm.v38n2.87589.

González Cussac, J. (2014), "Intromisión en la intimidad y CNI. Crítica al modelo español de control judicial previo", Inteligencia y Seguridad, 15 (enero-junio 2014) • Páginas 151-186• Issn: 1887-293x, Universidad de Valencia.

Navas Sánchez, M. (2011), “ ¿Inviolabilidad o Intimidad Domiciliaria? A propósito de la jurisprudencia constitucional sobre el derecho fundamental a la inviolabilidad del domicilio", UNED. Revista de Derecho Político Nº 81, mayo-agosto 2011, págs. 155-198.

Restrepo García, J. (2012), "El contenido del numeral $1^{\circ}$ del artículo 230 del CPP frente al bloque de constitucionalidad ¿Se respeta el derecho a la intimidad con la simple autorización expresa del propietario o tenedor de allanar su inmueble?", Revista Científica Guillermo de $\begin{array}{llllll}\text { Ockham, vol. 10, núm. 2, } & \text { 2, julio-diciembre, }\end{array}$ Universidad de San Buenaventura Cali, Colombia.

Riofrío Martínez-Villalba J.C. (2020), "Estado de extremísima excepción reconocido tácitamente en la constitución y su aplicación al sector privado”, Nuevo Derecho; 16(26): 1-14.

Sánchez Sanchez, A. (2020), "COVID-19 y su relación con la ciencia jurídica desde la perspectiva de México”, UTOPÍA Y PRAXIS LATINOAMERICANA. AÑO: 25, N EXTRA 11, 2020, pp. 48-64 REVISTA INTERNACIONAL DE FILOSOFÍA Y TEORÍA SOCIAL CESA-FCES-UNIVERSIDAD DEL ZULIA. MARACAIBO-VENEZUELA ISSN 1316-5216 / ISSN-e: 2477-9555.

Sánchez-Sánchez, M y W (2020), "Falencias en derechos humanos en tiempos de pandemia del coronavirus", Cátedra Villarreal-Lima-Perú, V.s. $\mathrm{N}^{\circ}$ 1, enero - junio 2020 ISSN 2310-4767.

Tribunal Supremo, Sala de lo Contencioso-Administrativo (2019), Sentencia 1343/2019, 10 oct. Rec. 2018/2017; "La solicitud de entrada y registro en domicilio acordada en un domicilio en estado de emergencia sanitaria San Martín-Tarapoto. Revista Científica Ratio lure, 1(1), 6277. https://doi.org/10.51252/rcri.v1i1.155 
procedimiento de comprobación e inspección debe atender a criterios de necesidad y proporcionalidad", Especial Directivos 1767 de fecha 01 dic 2019.

Universidad César Vallejo - Perú, Revisado en Biblioteca virtual, recursos digitales: http://eds.b.ebscohost.com/eds/results?vid=1\&sid=fb4e3f8d-78bd-48be-b6cc53493b9b62f5\%40sessionmgr103\&bquery=inviolabilidad+domicilio+covid+19\&bdata=Jmxhb mc9ZXMmdHlwZT0wJnNIYXJjaE1vZGU9QW5kJnNpdGU9ZWRzLWxpdmU\%3d 